\title{
An Assessment of Student Satisfaction with a Circulating Laptop Service
}

Since May of 2000, Colorado State University's (CSU) Morgan Library has provided a laptop computer lending service. In five years the service had expanded from 20 to 172 laptops. Although the service was deemed a success, users complained about slow laptop startups, lost data, and lost wireless connections. In the fall of 2005, the program was formally assessed using a customer satisfaction survey. This paper discusses the results of the survey and changes made to the service based on user feedback.

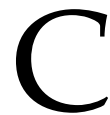

olorado State University (CSU) is a land-grant institution located in Fort Collins, Colorado. The CSU Libraries consist of the Morgan Library, the main library on the central campus; the Veterinary Teaching Branch Hospital Library at the Veterinary Hospital campus; and the Atmospheric Branch Library at the Foothills Campus. In 1997, Morgan Library completed a major renovation and expansion which provided a designated space for public desktop computers in an information commons environment. The library called this space the Electronic Information Center (EIC). Due to the popularity of the EIC , and with the intent of expanding computer access without expanding the computer lab, library staff began to explore the implementation of a laptop checkout service in 2000.

Library staff used Heather Lyle's (1999) article "Circulating Laptop Computers at West Virginia University" as a guide in planning the service. Development funds were used to purchase twenty laptop computers, and the 3COM Corporation donated fifteen wireless network access points. The laptops were to be used in Morgan Library on a wireless network maintained by the Library Technology Services department. These computers were to be circulated from the loan desk, the same desk used to check out books. Although the building is open to the public, use of the laptops was limited to university students and staff and for library in-house use only. All the public desktop computers and laptops use Microsoft Windows and Microsoft Office.

Maintaining the security of the libraries' network and students' personal data in a wireless environment was paramount. To maintain a secure computing environment

Louise Feldmann (louise.feldmann@colostate.edu) is the Business and Economics Librarian at Colorado State University Libraries. She serves as the College Liaison Librarian to the College of Business. Lindsey Wess (lindsey.wess@ colostate. edu) coordinates assistive technology services and manages the Information Desk and the Electronic Information Center at Colorado State University Libraries. Tom Moothart (tmoothar@ library.colostate.edu) is the Coordinator of On-site Services at Colorado State University Libraries. and present a standardized computing experience in the library, an application of Windows XP group policies was used. Currently, the laptop software is updated at least every semester using Symantec Ghost. Ghost copies a standardized image to every laptop even when the library owns a variety of computer models from the same manufacturer. Additionally, due to concerns over wireless computer security, Morgan Library implemented Cisco's Virtual Private Network (VPN) in 2004.

The laptop service was launched in May 2000. More than 22,000 laptop transactions occurred in the initial year. Since its inception, the use of the Morgan Library laptop service and the number of laptops available for checkout has steadily grown. Using student technology funds, the service had grown to 172 laptops and ten presentation kits consisting of a laptop, projector, and a portable screen. Circulation during the fall 2005 semester totaled 30,626 laptops and 102 presentation kits. In fiscal year 2005, 66,552 laptops and presentation kits were checked out. Based on the high circulation statistics and anecdotal evidence, the service appeared to be successful.

Although Morgan Library replaced laptops every three years and upgraded the wireless network, laptop support staff noted that users complained of slow laptop startups, lost data, and lost wireless connections. The researchers also noted that large numbers of users queued at the circulation desk at 5:00 p.m. even though large numbers of desktop computers were available in the EIC. A customer service satisfaction survey was developed to assess the service and test library staff's assumptions about the service. CSU had a student population of 25,616 students at the time of the survey.

\section{Literature review}

Much of the published literature discussing laptop services focuses on the implementation of laptop lending programs and was published from 2001 to 2003, when many libraries were beginning this service (Allmang 2003; Block 2001; Dugan 2001; Myers 2001; Oddy 2002; Vaughan and Burnes 2002; Williams 2003). These articles deal primarily with topics such as how to deal with start-up technological, staffing, and maintenance issues. They have minimal discussion of the service post-implementation.

Researchers who have surveyed users of university laptop lending services include DiRenzo (2002), Lyle (1999), Jordy (1998), Block (2001), Oddy (2002), and Monash University's Caulfield Library (2004). DiRenzo from the University of Akron only briefly discusses a survey they conducted with some information about additional software added as a result of their user comments. Lyle from West Virginia University discusses the percentage of respondents to particular questions such 
as what applications were used, problems encountered, and overall satisfaction with the service. Jordy's report provides in-depth analysis of the survey results from the University of North Carolina at Chapel Hill, but the focus of his survey is on the laptop service's impact on library employee work flow. Monash University's Caulfield Library survey focuses on wireless access and awareness of the program by patrons.

Other survey results found on university library Web sites include Southern New Hampshire University Library (West 2005) and Murray State University Library (2002). Additionally, the Monmouth University Library Web site (2003) provides discussion and written analysis of a survey they conducted prior to implementation of their service, a survey which was used to gather information and assess patron needs in order to aid in the construction and planning of their service.

From the survey results discussed in the literature and posted on Web sites, overall comments from users are very consistent with one another. Most users indicate that they use a loaned laptop computer rather than desktop computer for privacy and portability (Lyle 1999; Oddy 2002; West 2005). In addition, the responses from patrons are overwhelmingly positive and users appreciated having the service made available (Lyle 1999; Jordy1998; West 2005). Both West Virginia University and the University of North Carolina at Chapel Hill surveys found that 98 percent of respondents would check out a laptop again (Lyle 1999; Jordy 1998). Southern University of New Hampshire's survey indicated that 88 percent of those responding would check one out again (West 2005). Many respondents stated that a primary drawback of using the laptops was the slowness of connectivity (Lyle 1999; Monash 2004; Murray State 2002). The primary use of the laptops, reported in the surveys, was Microsoft Word (Lyle 1999; Jordy 1998; Oddy 2002).

There is a lack of published literature regarding laptop lending customer satisfaction surveys and analysis. This could be due to the relative newness of many

Table 1. How often do you use a library laptop?

\begin{tabular}{ll}
\hline Frequency & Percentage \\
\hline More than once a day & $3 \%$ \\
Daily & $30 \%$ \\
Weekly & $49 \%$ \\
Monthly & $15 \%$ \\
My first time & $3 \%$ \\
$\mathrm{~N}=172$ & \\
\hline
\end{tabular}

programs, the lack of university libraries that provide laptops, or the reliance on circulation statistics solely to assess the program. Articles that discuss circulation and usage statistics as an assessment indicator to judge the popularity of their programs include DiRenzo (2002), Dugan (2001), and Vaughan and Burnes (2002). Based on high circulation statistics and positive anecdotal evidence, it may appear that library users are pleased with laptop programs, and perhaps there has been a hesitation to survey users on a program that is perceived by those in the library as successful.

\section{Results}

With the strong emphasis on assessment at Colorado State University, it was decided to formally survey laptop users on their satisfaction with the program. The survey was distributed by the access services staff when the laptops were checked out from October 28, 2005, to November 28, 2005. This was a voluntary survey and the respondents were asked to complete one survey. Users returned 173 completed surveys. Undergraduates are the predominant audience for the laptop service; of the 173 returned surveys, 160 identified themselves as undergraduates.

As shown in table 1, the responses indicated that the library has a core of regular laptop users, with 33 percent using the laptops at least daily and 82 percent using the laptops at least weekly. Only 3 percent indicated that they were using a laptop for the first time. Many laptop users also utilized the EIC with 67 percent responding that they use the information commons at least weekly (see table 2).

The laptops were initially purchased with the intent that they would be used to support student team projects. Presentation kits with a laptop, projector, and portable screen were an extension of this idea and were also made available for checkout. Surprisingly, only 15 percent of

Table 2. How often do you use a library PC?

\begin{tabular}{ll}
\hline Frequency & Percentage \\
\hline More than once a day & $3 \%$ \\
Daily & $20 \%$ \\
Weekly & $44 \%$ \\
Monthly & $20 \%$ \\
Never & $13 \%$ \\
$\mathrm{~N}=169$ & \\
\hline
\end{tabular}




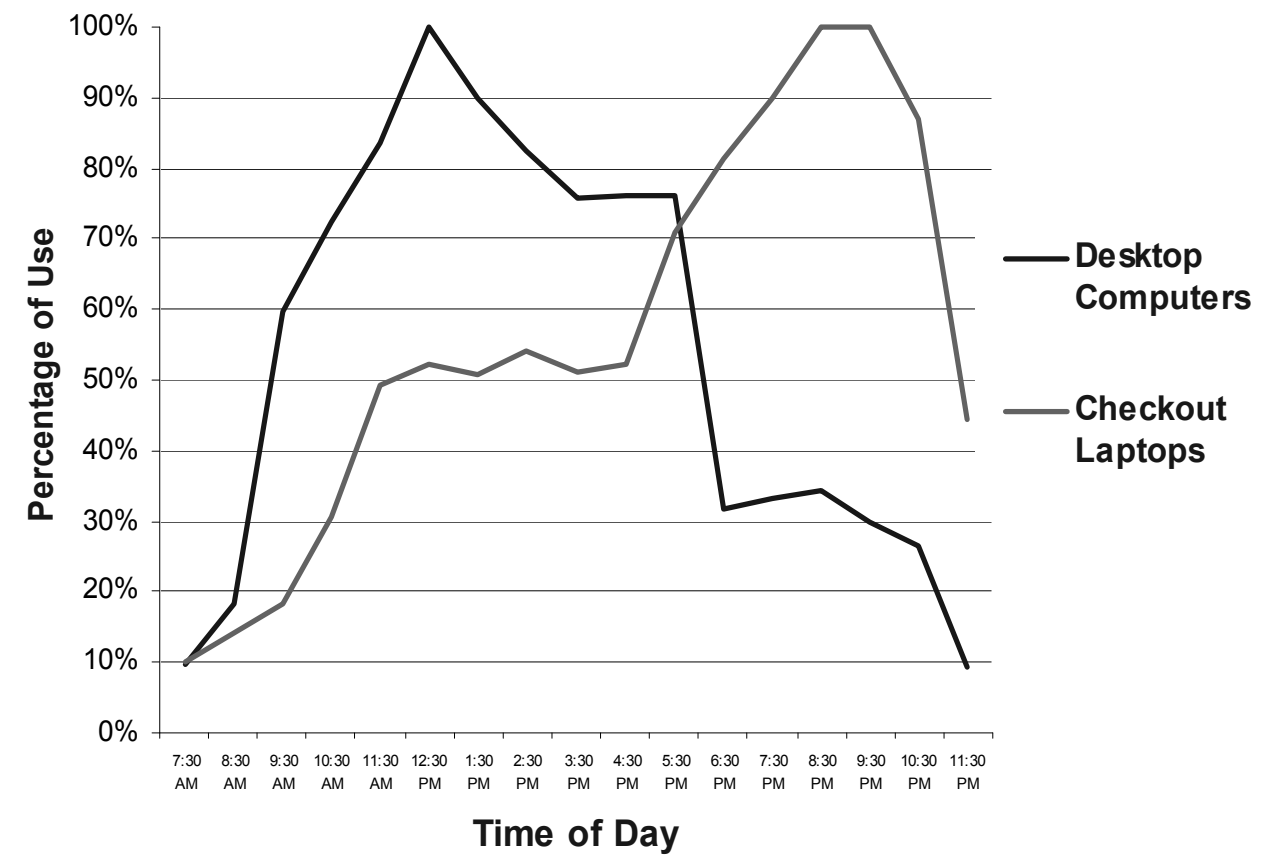

Figure 1. Computer use statistics for May 1, 2006.

of laptop over PC was because "I can take it to a table and spread out my notes vs. on a library PC." For many users, the desktops are too crowded to spread research material, and the EIC is too noisy for contemplative thought.

As can be noted from the use statistics, the public laptop program has been a very popular library service. Prior to the survey, the perception of the Morgan Library staff was that students were waiting in the evening for extended periods of time for a laptop. When the library expanded the laptop pool from 20 in 2000 to 172 in 2005, it had seemingly no effect on reducing the number of students waiting to use them. As can be seen in table 4 , when asked how long they had

the respondents noted that they were using the laptop with a group.

During evenings, it was observed by staff that students were regularly queuing and waiting for a laptop even though PCs were available in the library computer lab. Figure 1 shows an hourly use statistics for the desktop and laptop public computers. The usage of the desktop computer drops in the late afternoon, just as the use of the laptop computer increases.

Students were asked why they chose a laptop rather than a library PC and were allowed to choose from multiple answers. As can be seen in table 3, most students noted the advantages of portability and privacy. Five respondents wrote in the "other" category that they were able to work better in quieter areas, and ten mention that the computer lab workspace is limited. The dense use of space in the library computer lab has been noted by Morgan Library staff and students. The desktop surrounding each library PC only provides about three feet of workspace. One respondent explained the choice
Table 3. Why did you choose to use a laptop rather than a library PC?

\begin{tabular}{ll}
\hline Response & Number \\
\hline Portability & 41 \\
Privacy & 12 \\
Easier to work with a group & 7 \\
Portability and privacy & 54 \\
Portability and easier to work with a group & 10 \\
Portability, privacy, and easier to work with a group & 12 \\
\hline
\end{tabular}


Table 4. How long did you wait before you were able to check out your laptop?

\begin{tabular}{ll}
\hline Response & Percentage \\
\hline I did not wait & $74 \%$ \\
Less than one minute & $15 \%$ \\
One to four minutes & $11 \%$ \\
Five to ten minutes & $2 \%$ \\
More than ten minutes & $0 \%$ \\
$\mathrm{~N}=171$ & \\
\hline
\end{tabular}

respondents, when asked how the library could improve the laptop service many respondents requested that more laptops be purchased to decrease the wait. The library is struggling to determine the appropriate number of laptops to have available during peak use periods to reduce or eliminate wait times.

The library laptops are more problematic than the library desktop computers to support. The laptops are more fragile than the desktop computers and have the added complication of connecting to the wireless network. Every morning the Morgan Library's technology staff retrieves non-functioning laptops; library technicians regularly retrieve lost data due to malfunctioning laptops and unsophisticated computer users. The addition of the Virtual Private Network (VPN) connection to the laptop startup script files has slowed the boot-up to the wireless network. An effort has been made to ameliorate wireless "dead zones," but users still complain of being dropped from the wireless network. With these problems in mind, users were asked about the technical complications they have experienced with the library laptops.
The survey responses in tables 5 and 6 indicate a much lower percentage of users reporting technical problems than was anticipated. The technical staff's large volume of technical calls may reflect the volume of users rather than systematic problems with the laptop service. Surprisingly, 79 percent of the users reported rarely or never returning a non-functioning laptop. In addition, the library technicians have reported that no problems have been found on some of the laptops returned for repair. Some of the returned computers may be due to frustration with the slow connection to the wireless network.

Forty-five percent of respondents reported at least occasionally having problems connecting to the wireless network. From the inception of the laptop program, the library has experienced problems with the wireless technology. From its original fifteen wireless access points to its current twenty-nine, the library has struggled to meet the demand of additional library laptops and users' personal laptops. Many written comments on the surveys complained about the slow connection speed of the wireless network such as, "Find a way to make the boot-up process faster. I need to wait about five minutes for it to be totally booted and ready to use."

Even with the slow connection to the wireless network, 41 percent of students responding to the survey rated their satisfaction with the library's laptop service as excellent and 49 percent rated their satisfaction as good (see table 7).

\section{Discussion}

Even with 90 percent of our users rating the laptop service as good or excellent, the survey noted some problems that needed attention. The Morgan Library laptops seamlessly connect to a wireless network through a login script when the computer is turned on. A new script was written to

Table 5. How often have you experience problems saving files, connecting to the wireless network, or had a laptop that locked up or crashed?

\begin{tabular}{llll}
\hline Frequency & Saving files & $\begin{array}{l}\text { Wireless } \\
\text { connection }\end{array}$ & $\begin{array}{l}\text { Locked up or } \\
\text { crashed }\end{array}$ \\
\hline Often & $<1 \%$ & $5 \%$ & $<1 \%$ \\
Occasionally & $8 \%$ & $40 \%$ & $17 \%$ \\
Rarely & $33 \%$ & $32 \%$ & $35 \%$ \\
Never & $58 \%$ & $24 \%$ & $49 \%$ \\
$\mathrm{~N}=$ & 165 & 165 & 163 \\
\hline
\end{tabular}

Table 6. How often have you returned a library laptop that was not working properly?

\begin{tabular}{ll}
\hline Frequency & Percentage \\
\hline Often & $4 \%$ \\
Occasionally & $18 \%$ \\
Rarely & $30 \%$ \\
Never & $49 \%$ \\
$\mathrm{~N}=165$ & \\
\hline
\end{tabular}


Table 7. Please rate your satisfaction with the laptop service.

\begin{tabular}{ll}
\hline Response & Percentage \\
\hline Excellent & $41 \%$ \\
Good & $49 \%$ \\
Neutral & $7 \%$ \\
Poor & $2 \%$ \\
Very Poor & $<1 \%$ \\
$\mathrm{~N}=166$ & \\
\hline
\end{tabular}

allow the connection and authentication to the Cisco Virtual Private Network (VPN) client. During testing it was found that some laptops took as long as ten minutes to connect to the wireless network, which resulted in numerous survey respondents commenting on our slow wireless network. To help correct this problem, the library's network staff changed each laptop's user profile from a mandatory roaming profile to a local profile and simplified the login script. The laptops connected faster to the wireless network with the new script, but they still did not meet the students' expectations. In the fall of 2006, the library network staff moved the laptops from VPN to Wi-Fi Protected Access (WPA) wireless security, and laptop login time to the wireless network dropped to under two minutes. The number of customer complaints dropped dramatically after implementing WPA.

Additional access points were purchased to improve connectivity in Morgan Library's wireless "dead zones." In January 2006, the University's Central Computing Services audited the wireless network after continued wireless connectivity complaints. The audit recommended reconfiguring the access points channel assignments. In many cases it was found that the same channel had been assigned to access points adjacent to each other, ultimately compromising laptop connectivity. The audit also discovered noise interference on the wireless network from a $2.4-\mathrm{GHz}$ cordless phone used by the loan desk staff. The phone was replaced with a $5.8-\mathrm{GHz}$ one, which has resulted in fewer dropped connections near the loan desk.

Supporting almost 200 laptops has introduced several problems in the library. The Morgan Library building was not designed to support the use of large numbers of laptops. Because it is impractical for the loan desk to charge nearly 200 laptop batteries throughout the day, laptops available for checkout must be connected to electrical outlets. These are seldom near study tables, and students are forced to crawl underneath tables to locate power or stretch adapter cords across aisles. A space plan for the Morgan Library is being developed that will increase the number of outlets near study tables. In the meantime, 100 power strips were added to tables used heavily by laptop users.

The loan desk staff is very efficient at circulating, but has less success at troubleshooting technical problems. When the laptop service was first implemented, large numbers of laptops were not available due to servicing reasons. The public laptop downtime was lowered by hiring additional library technology students. A one-day onsite repair service agreement was purchased from the manufacturer which resulted in many equipment repairs being completed within 48 hours. In order to reduce the downtime further, a plan to replace some loan desk student workers with library technology students is being evaluated. The technology students will be able to troubleshoot connectivity and hardware problems with the users when they return the defective computers to the loan desk. If a computer needs additional service, it can be handled immediately, which will allow more laptops for checkout since fewer will be removed for repair.

When the laptop service was first envisioned, it was seen as a great service for those working in groups. As can be seen in table 3, very few students are using the laptops in a group setting. In survey written comments, students emphasize that they enjoy the portability and privacy enabled by using a laptop. The Morgan Library EIC is cramped and noisy, with the configuration allowing very little room for students to spread out research materials and notes for writing. The Morgan Library space plan takes these issues into consideration and recommends reconfiguring the EIC to lessen the noise and provide writing space near computers. This is intended to improve the student library experience and encourage students to use the desktop computers during the evenings when lines form for the laptops.

In order to decrease the current laptop queue at the loan desk, more laptops will be added. As a result of survey comments requesting Apple computers, five Mac PowerBooks were added to the library's laptop fleet. In addition, as Morgan Library adds more checkout laptops and the number of students arriving on campus with wireless laptops increases, the wireless infrastructure will need to be upgraded. Upgrading the wireless access points to standard $802.11 \mathrm{~g}$ has been implemented.

Updating each laptop with a new hardrive image has become problematic as the number of laptops has increased. The wireless network capacity is not large enough for the Ghost software to transmit the image to multiple laptops, and so each laptop must be physically attached to the library network. Initially, when library technology services attempted imaging many laptops at once, it took six to eight hours and required up to eight staff members. This method of large-scale laptop imaging was so network intensive that it had to be performed when the library was closed to avoid disrupting 
public Internet use. Now imaging the laptop fleet is done piecemeal, twenty to thirty laptops at a time, in order to minimize complications with the Ghost process and multicasting through the network switches. Due to the staff time required, laptop software is not updated as often as the users would like. Technological solutions continue to be investigated that will decrease the labor and network intensity of imaging.

\section{Conclusion}

The Morgan Library Laptop service was established in 2000 and has been a very popular addition to the library's services. As an example of its popularity, in fiscal year 2005 the laptops circulated 66,552 times. Student government continues to support the use of student technology fees to support and expand the fleet of laptops. This survey was an attempt to assess users' perceptions of the service and identify areas that need improvement. The survey found that students rarely wait more than a few minutes for a laptop, and in open-ended survey questions, students noted that they waited for computers only during peak use periods. While relatively few survey respondents experienced technical difficulties with the laptops and wireless network, slow wireless connection time was a concern that students noted in the open comments section of the survey. Overall, the students gave the laptop service a very high rating. When asked to suggest improvements to the service, many respondents recommended purchasing more laptops.

The libraries made several changes to improve the laptop service based on survey responses. Changes have been made to the login script files, wireless network, and security protocol to speed and stabilize the wireless connection process. Additional wireless access points will be added to the building and all access points will be upgraded to the $802.11 \mathrm{~g}$ standard. In addition, five Mac PowerBooks have been added to the fleet of Windowsbased laptops. The library continues to investigate new service models to circulate and maintain the laptops.

\section{Works Cited}

Allmang, Nancy. 2003. Our plan for a wireless loan service. Computer in Libraries 23, no. 3: 20-25.

Block, Karla J. 2001. Laptops for loan: The experience of a multilibrary project. Journal of Interlibrary Loan, Document Delivery, and Information 12, no. 1: 1-12.

DiRenzo, Susan. 2002. A wireless laptop-lending program: The University of Akron experience. Technical Services Quarterly 20, no. 2: 1-12.

Dugan, Robert E. 2001. Managing laptops and the wireless network at the Mildred F. Sawyer Library. Journal of Academic Librarianship 27, no. 4: 295-298.

Jordy, Matthew L. 1998. The impact of user support needs on a large academic workflow as a result of a laptop check-out program. Master's thesis, University of North Carolina.

Lyle, Heather. 1999. Circulating laptop computers at West Virginia University. Information Outlook 3, no. 11: 30-32.

Myers, Penelope. 2001. Laptop rental program, Temple University Libraries. Journal of Interlibrary Loan, Document Delivery, and Information Supply 12, no. 1: 35-40.

Monash University Caulfield Library. 2004. Laptop users and wireless network survey. www.its.monash.edu.au/staff/networks / wireless / review/caul-lapandnetsurvey.pdf (accessed June 8, 2005).

Monmouth University. 2003. Testing the wireless waters: A survey of potential users before the implementation of a wireless notebook computer lending program in an academic library. http:/ / bluehawk.monmouth.edu/ hholden/WWL/wireless_survey_results.html (accessed June 8, 2005).

Murray State University. 2002. Library laptop computer usage survey results. www.murraystate.edu/msml/laptopsurv. htm (accessed June 8, 2005).

Oddy, Elizabeth Carley. 2002. Laptops for loan. Library and Information Update 1, no. 4: 54-55.

Vaughn, James B., and Brett Burnes. 2002. Bringing them in and checking them out: Laptop use in the modern academic library. Information Technology and Libraries 21, no. 2: 52-62.

West, Carol. 2005. Librarians pleased with results of student survey. Southern New Hampshire University. www.snhu. edu/3174/asp (accessed June 8, 2005).

Williams, Joe. 2003. Taming the wireless frontier: PDAs, tablets, and laptops at home on the range. Computers in Libraries 23, no. 3: 10-12, 62-64. 